\title{
Factors Influencing Demand for Medical Cannabis Use among Cancer Patients in the North of Thailand
}

\author{
Alongkorn Sukrueangkul ${ }^{1}$, Nitchatorn Panomai ${ }^{2 *}$, Wongsa Laohasiriwong ${ }^{2}$, \\ Chutikan Sakphisutthikul', Surachai Phimha ${ }^{2}$
}

\begin{abstract}
Objective: Cancer treatments often cause side effects. Cannabis is a plant that has been studied and used to treat and relieve side effects from modern medicine. Medical cannabis (MC) was legalized in Thailand in 2019 with limited research on demand for its use. Therefore, this study aimed to identify factors associated with demand for MC use among cancer patients in the North of Thailand. Methods: This analytical cross-sectional study administered a multistage random sampling to recruit 1,284 cancer patients in northern Thailand to response a self-administered structured questionnaire. Generalized Linear Mixed Model (GLMM) was used to identify the determinants of demand for MC use among the population, presented adjusted odds ratios (adj.OR), 95\% confidence intervals (95\% CI), and p-values. Result: Nearly half of the respondents reported demand to use MC (44.0\%). The factors that were significantly associated with demand to use MC included had high levels of health literacy about MC (adj.OR =5.70; 95\% CI: 4.08 to 7.96), higher levels of social support (adj.OR $=5.50 ; 95 \% \mathrm{CI}: 3.60$ to 8.39), positive attitudes toward $\mathrm{MC}$ use (adj.OR $=2.56 ; 95 \% \mathrm{CI}: 1.83$ to 3.56 ), aged less than 30 (adj.OR $=1.89 ; 95 \% \mathrm{CI}$ : 1.21 to 2.93 ), diagnosis with cancerfor more than 12 months ago (adj.OR $=1.73 ; 95 \%$ CI: 1.19 to 2.52 ) when controlling effect of other covariates. Conclusion: We found substantial demand for MC use among cancer patients. Health literacy,social support, attitudes about MC, age, and duration of having cancer were significantly associated with demand for MC use. Therefore, improving health literacy and social support, especially among older cancer patients, could help increasing demand for MC as a complementary medicine to treat cancers.
\end{abstract}

Keywords: Alternative medicine- contemporary medicine- ganja- marijuana

Asian Pac J Cancer Prev, 23 (1), 319-325

\section{Introduction}

While significant advancements in cancer therapy have been achieved, cancerremains a major medical and public health problem (Markham et al., 2020). Malignancies ranked as the second leading cause of death worldwide in 2018, accounting for an estimatedof 9.6 million deaths (WHO, 2018). The burden of cancer in Thailand is similarly significant, with more than 170,000 cancer cases and 114,000 cancer deathsrecorded in 2018, comprising over $36 \%$ of the prematuredeaths attributable to non-communicable disease (WHO, 2020).Cancers of the liver, lung, colon and rectum, breast, stomach, and gallbladder are the most common sites for malignancy in Thailand, each contributing from 1 to $5 \%$ of all total deaths.Incidence of cancer types differs among the country's regionsdue to differences in cultural and lifestyle patterns (Virani et al., 2017). Liver and lung cancers, in particular,are expected to increase in the north and northeast of the country.The magnitude of the problem requires not only sufficient access to the curative sector but also the integration of public health into optimal efforts for cancer diagnosis and therapy. The main goal should be to prolong the patient's life with the best possible quality of life (QOL) ("WHO | Cancer control. Knowledge into action," n.d.).

Cannabis is a plant that has been studied and used to relieve side effects from existing cancer treatments. The primary group of active chemicalsin cannabis is cannabinoids with several of these compounds used as medicinal substances. The two most commonly used compounds are delta-9 tetrahydrocannabinol (THC) and Cannabidiol (CBD), with both chemicals acting through the endocannabinoid system (Lal et al., 2021). These cannabinoids have been used as a pain reliever, antiemetic drug in chemotherapy treatment, appetite stimulant, stress reliever, and sleep aid (Abrams and Guzman, 2015). The use of cannabis in cancer patients, however, can

${ }^{1}$ Doctor of Public Health Program, Faculty of Public Health, KhonKaen University, Thailand. ${ }^{2}$ Department of Public Health Administration, Health Promotion, and Nutrition, Faculty of Public Health, KhonKaen University, KhonKaen, Thailand. *For Correspondence: rappan@kku.ac.th 
cause side effects such as dry mouth, nausea, vomiting, confusion. Special attention is needed for older adults with cardiovascular disease in whom palpitations, tachycardia, high blood pressure can occur, as well as people with mental illness (Whiting et al.,2015; Sexton et al., 2016).

In Thailand, medical cannabis (MC) remains a new concept with only limited research available. The Thai government authorized the use of cannabis for medical purposes in 2019. The rapid introduction of $\mathrm{MC}$ has led to misconceptions and controversies, such as 1) the belief that cannabis can cure all diseases, 2) the growth of illegal cannabis trading through online media, and 3) the pursuit of marijuana among ineligible patients (SuphanchaimatandPavasuthipaisit, 2018; SaengkhamandOngkasingh, 2020).

$\mathrm{MC}$ use among cancer patients can be considered a form of complementary and alternative medicine (CAM). Demographics associated with use of CAM among cancer patients around the world have shown some notable trends. For example, young women with cancer in Italy were more like to use CAM therapies, including dietary supplements and herbs (Bonacchi et al.,2014). Similarly, in Ghana, being young, married, female, and having a high level of education were all factors that led to increased CAM use following cancer diagnosis (Yarneyet al.,2013). These trends mimic trends in the broader population. For example, in Norway, CAM usage was higher in younger, female, and educated individuals (Kristoffersen et al.,2021).

Clinical characteristics are also important. Patients that have undergone treatment for a long duration of time or had less success in treatment were more like to have higher awareness about CAM, which can affect subsequent usage (Choi et al.,2021). An advanced stage of cancer has been shown to be strongly related to CAM use (Naja et al.,2015). Increased usage of CAM has been associated among rural elderly cancer and among those who have more than one comorbidity (Ayele et al., 2017). Besides demographics and clinical characteristics, social attitudes and previous experience can be an important factor in determining CAM usage. For example, social networks and encouragement from family can strongly influence choices to use CAM (Labidi et al.,2020). Expectations of CAM effectiveness or dissatisfaction with current treatment have also been shown to increase the use of CAM (Tangkiatkumjai et al.,2020; Bauml et al., 2015). However, health literacy regarding CAM is also important, with young men having lower levels of health literacy (Sharoni et al.,2019).

Overall, while cultural and societal differences affect attitudes towards CAM among cancer patients, some similar trends are observed globally, including generally being associated with females, younger age, higher income, more advanced stages of cancer, and previous experience with or knowledge about CAM. Considering cannabis use in particular, MC may be slightly different. For example, $\mathrm{MC}$ has been shown to be more common among males compared to females (Haug et al.,2017). Furthermore, there may be higher levels of stigma associated with MC use (Leos-Toro et al., 2018).

Therefore, given the importance of culture, demographics, and laws, as well as the relative novelty of MC in Thailand, there is a need to understand the role of these factors in affecting MC use among cancer patients in Thailand. Given the higher incidence of cancer in northern Thailand relative to the rest of the country, we were interested in studying demand of MC use among cancer patients in the region. This study aimed to identify factors associated with demand of MC use among cancer patients in northern Thailand.

\section{Materials and Methods}

\section{Study design}

This cross-sectional study was conducted using an anonymous paper-based survey administered in outpatient cancer clinics located at six public hospitals within northern Thailand (within Ministry of Public Health Regions 1 to 3 ). The six hospitals were multistage randomly selected. ied

\section{Participants}

Any cancer patient with a cancer diagnosis, receiving treatment at one of the studied hospitals, aged 18 or older, and able to read and write in Thai were eligible for inclusion in the study. Recruitment took place between July 2020 and January 2021. Participants were recruited by register nurse. Participants who received end stage cancer diagnosis or whose severe symptoms prevented them from providing information were excluded.

\section{Instrument}

Data was collected using a self-administered questionnaire that include 6 items with structured question format about MC. Social support were assessed using social support questionnaire, which was coded into a score from 20 to 100 . Attitudes were assessed using attitude about MC questionnaires, which was coded into a score from 15 to 45 . Knowledge about MC were assessed using knowledge about MC questionnaires, which was coded into a score from 0 to 20 , and health literacy about MC, were assessed using health literacy instruments, which was coded into a score from 47 to 188 and score from all questionnaires were converted to percentages. The survey was developed by the project team specifically for this research based on research questions and relevant literature. The questionnaire was test by five experts for validity. The questionnaire was trialed to test the reliability. The Cronbach's Alpha was 0.88 for sociodemographic factors, 0.86 for social support, 0.81 for attitudes, 0.94 for health literacy, and 0.84 for demand of MC use among cancer patients. The Kuder - Richardson was 0.75 for knowledge about $\mathrm{MC}$ use questionnaires.

\section{Data Analysis}

Data was entered into a database using STATA software with $100 \%$ of data entry checked for accuracy. Simple logistic regression was used to identify association between each individual independent variable and demand of MC use. The independent factors that had p-value smaller than 0.25 (Bursac et al.,2008) were processed in the multivariable analysis using a generalized linear 
mixed model (GLMM) to identify factors associated with demand of MC use when controlling for the effect of other covariates. The magnitude of effectswere presented as adjusted odds ratio (adj.OR) and 95\% confidence interval (CI), using a statistical significance level $\alpha=0.05$.

\section{Ethical considerations}

This research has been approved by the KhonKaen University Ethics Committee in Human Research base on the Declaration of Helsinki and the ICH Good Clinical Practice Guidelines. Record No. 4.3.01: 23/2020, Reference No. HE632157.

\section{Results}

\section{Patient Characteristics}

In total, 1,284 cancer patients were included in the final analysis.Most of the participants were females $(61.7 \%)$, with a mean age of $58.3 \pm 13.0$ years (Table 1$)$. Most reported being currently married or in domestic partnership (74.3\%), having completed only primary school (64.7\%), and earning amonthly income less than or equal to 10,000 THB (around 312 USD). Among possible health coverage schemes, around three quarters (76.3\%) were covered under the Universal Coverage Scheme, which provides public health insurance coverage to those ineligibles for social health insurance (Social Security Scheme) or government fringe benefits (Civil Servant Medical Benefit Scheme). Many participants $(69.4 \%)$ hada comorbidity in addition to cancer. The most common cancer sites were breast $(30.8 \%)$, followed by colorectal $(20.9 \%)$, and lung $(9.7 \%)$. Theaverage time from diagnosis of cancer was 10.23 months with a large amount of variability ( \pm 16.57 months).Most participants $(69.4 \%)$ were categorized into a group with cancer stage of II, III, or IV. Treatment included chemotherapy (59.3\%), radiation therapy $(19.8 \%)$, and surgery $(13.2 \%)$. Almost one-third of participants had a high level of social support. (Table 1).

Knowledge, Attitudes, Health Literacy, and Demand for $M C$

A large majority of respondents (88.24\%) reported having received information about $\mathrm{MC}$ (Table 1). The most common source of MC information was family (75.2\%), television (52.6\%), and social media (37.1\%). Attitudes and knowledge about MC were well distributed with nearly equal numbers in the groups. Concerning health literacy, around half $(56.5 \%)$ of the sample was categorized as having problematic health literacy. Overall, less than half of participants, $(44.0 \%)$ report having a demand for MC (Table 1).

\section{Bivariable analysis of factors associated with demand} for MC use

Simple logistic regression was used to identify association between each individual independent variable and demand of MC use (Table 2). The independent factors that had p-value smaller than 0.25 were: age less than $30(\mathrm{OR}=3.48 ; 95 \% \mathrm{CI}: 1.72-7.03: \mathrm{p}$-value $=0.001)$, education higher than primary school $(\mathrm{OR}=1.28 ; 95 \%$
Demand for Medical Cannabis Use in Northern Thailand

Table 1. Socio-Demographic Factors among Cancer Patients in the Northern of Thailand. $(n=1,284)$

\begin{tabular}{|c|c|c|}
\hline Factors & Number & Percentage \\
\hline \multicolumn{3}{|l|}{ Gender } \\
\hline Female & 792 & 61.7 \\
\hline Male & 492 & 38.3 \\
\hline \multicolumn{3}{|l|}{ Age group (years) } \\
\hline$<30$ & 40 & 3.1 \\
\hline$\geq 30$ & 1,244 & 96.9 \\
\hline \multicolumn{3}{|l|}{ Mean \pm S.D. $=58.3 \pm 13.0$} \\
\hline \multicolumn{3}{|l|}{ Current relationship status } \\
\hline Married/domestic partnership & 954 & 74.3 \\
\hline Divorced/separated/widowed & 227 & 17.7 \\
\hline Single & 103 & 8 \\
\hline \multicolumn{3}{|l|}{ Highest education level } \\
\hline Primary school & 831 & 64.7 \\
\hline Junior high school and higher & 453 & 35.3 \\
\hline \multicolumn{3}{|l|}{ Monthly income (THB) } \\
\hline$<10,000$ & 867 & 67.5 \\
\hline$\geq 10,000$ & 417 & 32.5 \\
\hline \multicolumn{3}{|c|}{ Mean \pm S.D. $=11,425.25 \pm 13,598.54$} \\
\hline \multicolumn{3}{|l|}{ Scheme } \\
\hline Universal Coverage & 979 & 76.3 \\
\hline Civil Servant Medical Benefit & 195 & 15.2 \\
\hline Social Security & 110 & 8.6 \\
\hline \multicolumn{3}{|l|}{ Health status } \\
\hline Comorbidity & 891 & 69.4 \\
\hline No comorbidity & 393 & 30.6 \\
\hline \multicolumn{3}{|l|}{ Primary cancer site } \\
\hline Breast & 395 & 30.8 \\
\hline Colorectal & 268 & 20.9 \\
\hline Lung & 124 & 9.7 \\
\hline Lymphoma & 92 & 7.2 \\
\hline Cervical & 74 & 5.8 \\
\hline Other & 327 & 25.4 \\
\hline \multicolumn{3}{|c|}{ Time from diagnosis with cancer (month) } \\
\hline$<12$ & 1,072 & 62.6 \\
\hline$\geq 12$ & 212 & 37.4 \\
\hline \multicolumn{3}{|l|}{ Mean \pm S.D. $=10.27 \pm 16.57$} \\
\hline \multicolumn{3}{|l|}{ Current treatment received } \\
\hline Chemotherapy & 762 & 59.3 \\
\hline Radiation therapy & 254 & 19.8 \\
\hline Surgery & 168 & 13.2 \\
\hline Other & 100 & 7.8 \\
\hline \multicolumn{3}{|l|}{ Stage of Cancer } \\
\hline Unknown & 179 & 13.9 \\
\hline In situ & 91 & 7.1 \\
\hline Stage I & 200 & 15.6 \\
\hline Stage II-IV & 814 & 69.4 \\
\hline \multicolumn{3}{|c|}{ Received information about cannabis } \\
\hline Yes & 1,133 & 88.2 \\
\hline No & 151 & 11.8 \\
\hline
\end{tabular}

Asian Pacific Journal of Cancer Prevention, Vol 23 
Table 1. Continued

\begin{tabular}{|c|c|c|}
\hline Factors & Number & Percentage \\
\hline \multicolumn{3}{|l|}{ Source of MC information } \\
\hline Family & 965 & 75.2 \\
\hline Television & 675 & 52.6 \\
\hline Social media & 476 & 37.1 \\
\hline $\begin{array}{l}\text { Doctor, pharmacist, and medical } \\
\text { staff }\end{array}$ & 142 & 11.1 \\
\hline Newspaper/ brochures & 132 & 10.3 \\
\hline Radio & 89 & 6.9 \\
\hline Academic article & 83 & 6.5 \\
\hline Thai traditional medicine & 75 & 5.8 \\
\hline Other & 27 & 2.1 \\
\hline \multicolumn{3}{|l|}{ Social support } \\
\hline Low (less than 60 percentage) & 467 & 36.4 \\
\hline Moderate (60-79 percentage) & 347 & 27 \\
\hline $\begin{array}{l}\text { High (greater than or equal to } \\
80 \text { percentage) }\end{array}$ & 470 & 36.6 \\
\hline \multicolumn{3}{|l|}{ Mean \pm S.D. $=67.48 \pm 13.44$} \\
\hline \multicolumn{3}{|l|}{ Attitude toward MC } \\
\hline Poor (less than 60 percentage) & 360 & 28 \\
\hline Fair (60-79 percentage) & 439 & 34.2 \\
\hline $\begin{array}{l}\text { Good (greater than or equal to } \\
80 \text { percentage) }\end{array}$ & 485 & 37.8 \\
\hline \multicolumn{3}{|l|}{ Mean \pm S.D. $=69.78 \pm 15.47$} \\
\hline \multicolumn{3}{|l|}{ Knowledge about MC } \\
\hline Low (less than 60 percentage) & 386 & 30.1 \\
\hline Average (60-79 percentage) & 471 & 36.7 \\
\hline $\begin{array}{l}\text { Good (greater than or equal to } \\
80 \text { percentage) }\end{array}$ & 427 & 33.3 \\
\hline \multicolumn{3}{|l|}{ Mean \pm S.D. $=60.22 \pm 21.00$} \\
\hline \multicolumn{3}{|c|}{ Health Literacy for medicinal cannabis use dimensions } \\
\hline Inadequate ( $0-50$ percentage $)$ & 189 & 14.7 \\
\hline Problematic (51-65 percentage) & 726 & 56.5 \\
\hline Sufficient (66-84 percentage) & 191 & 14.9 \\
\hline $\begin{array}{l}\text { Excellent (85 percentage and } \\
\text { over) }\end{array}$ & 178 & 13.9 \\
\hline \multicolumn{3}{|l|}{ Mean \pm S.D. $=63.50 \pm 12.84$} \\
\hline \multicolumn{3}{|l|}{ Demand to $\mathrm{MC}$ use } \\
\hline No & 719 & 56 \\
\hline Yes & 565 & 44 \\
\hline
\end{tabular}

CI: $1.01-1.61: p$-value $=0.038)$, receiving health coverage outside the Universal Coverage Scheme (OR $=1.63 ; 95 \%$ CI: $1.27-2.10: \mathrm{p}$-value $<0.001)$, not have comorbidity $(\mathrm{OR}=1.33$; $95 \% \mathrm{CI}$ : $1.05-1.68$ : $\mathrm{p}$-value $=0.020)$, time from cancer diagnosis of 12 months or more $(\mathrm{OR}=1.40 ; 95 \% \mathrm{CI}: 1.04-1.88$ : $\mathrm{p}$-value $=0.026)$, having previously received information about $\mathrm{MC}(\mathrm{OR}=$ 1.58; 95\% CI: $1.10-2.25$ : p-value $=0.012)$, high level of social support $(\mathrm{OR}=6.66 ; 95 \% \mathrm{CI}$ : $5.06-8.77$; p-value $<0.001)$, good attitude toward MC use $(\mathrm{OR}=4.03 ; 95 \%$ CI: 3.04 - 5.34; p-value $<0.001)$, good knowledge about $\mathrm{MC}$ use $(\mathrm{OR}=2.76 ; 95 \% \mathrm{CI}: 2.13-3.58 ; \mathrm{p}$-value $<0.001)$, and adequate to excellent levels of health literacy about $\mathrm{MC}(\mathrm{OR}=10.92 ; 95 \% \mathrm{CI}: 8.09-14.73$; $\mathrm{p}$-value $<0.001)$. (Table 2.)

\section{Multivariable analysis of factors associated with demand for MC use}

The multivariable analysis using GLMM with backward elimination indicated that the factors significantly associated with demand to MC use were: young age of $<30$ years old (adj.OR $=1.89 ; 95 \% \mathrm{CI}$ : 1.21 to 2.93 ), long time from diagnosis with cancer (adj. OR $=1.73 ; 95 \%$ CI: 1.19 to 2.52 ), high social support (adj.OR $=5.50 ; 95 \%$ CI: 3.60 to 8.39 ), positive attitude toward MC use (adj.OR = 2.56; 95\% CI: 1.83 to 3.56), and Adequate- excellenthealth literacy about MC (adj. $\mathrm{OR}=5.70 ; 95 \% \mathrm{CI}: 4.08$ to 7.96$)$ when controlling other covariates (Table 3).

\section{Discussion}

We found that $44.0 \%$ of cancer patients in the North of Thailand reported having demand for MC use. This finding was comparable to actual marijuana usage among cancer patients reported in Alberta, Canada (Martell et al., 2018) and in the US(Tringale et al., 2017). Those countries have a longer history of MC legalization compared to Thailand. The Thai government has only recently legalized MC use in 2019. Demand for MC use in Thai society may be enhanced by recent attention. After controlling the covariates with backward elimination in the multivariate analysis, five variables were significantly associated with demand for MC use among cancer patients in northern Thailand. Those variables were higher health literacy about MC, higher social support, positive attitude toward MC use, young age, and longer time from diagnosis with cancers.

In our study, we also found that cancer patients that had adequate to excellent levels of health literacy about $\mathrm{MC}$ were 5.70 times more likely to report having demand to use MC when compared with those with insufficient and problematic levels of health literacy about MC. Health literacy has previously been shown to positively correlate with CAM usage (Smith et al., 2019). Another study reported that CAM usage was significantly associated with adequate levels of health literacy among whites in the U.S. (Bains et al., 2011).

People who reported moderate to high levels of social support were 5.50 times more likely to report demand for MC use when compared with those with low levels of social support. Social support has been shown to be related to CAM use in cancer patients (Reblin et al., 2019). It may be that most of the participants received social support from close friends and family members who provided information about MC products for patients to use.

Those participants who reported a fair to good attitude toward MC use were 2.56 times more likely to report demand for MC use when compared to those with poor attitudes toward MC use. A previous study measuring intention to use $\mathrm{MC}$ in northeast Thailand reported that those with positive attitudes toward MC were 3.74 times 
Table 2. The Bivariable Analysis of Factors Associated with Demand to MC Use among Cancer Patients in the Northern of Thailand. $(\mathrm{n}=1,284)$

\begin{tabular}{|c|c|c|c|c|c|}
\hline Factors & Number & $\%$ Demand to MC use & Crude OR & $95 \% \mathrm{CI}$ & P-value \\
\hline Sex & & & & & 0.184 \\
\hline Male & 492 & 46.34 & 1 & - & \\
\hline Female & 792 & 42.55 & 0.85 & $0.68-1.07$ & \\
\hline Age (years) & & & & & 0.001 \\
\hline$\geq 30$ & 1,244 & 43.09 & 1 & - & \\
\hline$<30$ & 40 & 72.5 & 3.48 & $1.72-7.03$ & \\
\hline Current relationship status & & & & & 0.236 \\
\hline Single/divorced/separated/widowed & 330 & 41.21 & 1 & - & \\
\hline Married/domestic partnership & 954 & 44.97 & 1.16 & $0.90-1.50$ & \\
\hline Completed education & & & & & 0.038 \\
\hline Primary school & 831 & 41.88 & 1 & - & \\
\hline $\begin{array}{l}\text { Junior/senior high school/trade or vocational } \\
\text { training/University degree }\end{array}$ & 453 & 47.9 & 1.27 & $1.01-1.60$ & \\
\hline Scheme & & & & & 0 \\
\hline Universal coverage & 948 & 40.82 & 1 & - & \\
\hline $\begin{array}{l}\text { Civil servant medical benefit /social security } \\
\text { scheme }\end{array}$ & 336 & 52.98 & 1.63 & $1.27-2.09$ & \\
\hline Monthly income (THB) & & & & & 0.105 \\
\hline$\leq 10,000$ & 867 & 42.45 & 1 & - & \\
\hline$\geq 10,001$ & 417 & 47.24 & 1.21 & $0.96-1.53$ & \\
\hline Health status & & & & & 0.02 \\
\hline Comorbidity & 891 & 41.86 & 1 & - & \\
\hline Not have comorbidity & 393 & 48.85 & 1.32 & $1.04-1.68$ & \\
\hline Time from diagnosis with cancer (month) & & & & & 0.026 \\
\hline$<12$ & 1,072 & 42.63 & 1 & - & \\
\hline$\geq 12$ & 212 & 50.94 & 1.39 & $1.04-1.87$ & \\
\hline Received information about cannabis & & & & & 0.012 \\
\hline No & 151 & 34.44 & 1 & - & \\
\hline Yes & 1,133 & 45.28 & 1.57 & $1.10-2.24$ & \\
\hline Social support & & & & & 0 \\
\hline Low & 467 & 17.77 & 1 & - & \\
\hline Moderate to high & 817 & 59 & 6.65 & $5.05-8.76$ & \\
\hline Attitude toward MC & & & & & 0 \\
\hline Poor & 360 & 21.67 & 1 & - & \\
\hline Fair to Good & 924 & 52.71 & 4.02 & $3.03-5.34$ & \\
\hline Knowledge about MC use & & & & & 0 \\
\hline Low & 386 & 27.46 & 1 & - & \\
\hline Average to good & 898 & 51.11 & 2.76 & $2.13-3.57$ & \\
\hline \multicolumn{6}{|l|}{ Health literacy about MC } \\
\hline Inadequate- Problematic & 915 & 28.85 & 1 & - & 0 \\
\hline Adequate- Excellent & 369 & 81.57 & 10.91 & $8.09-14.72$ & \\
\hline
\end{tabular}

more likely to report having an intention to use $\mathrm{MC}$ when compared with those with poor to fair levels (Rakpanich et al., 2020).

Cancer patients aged less than 30 years were 1.89 times more likely to reportdemand for MC use when compared with those aged 30 years or older in our study. Youth has commonly been reported as a factor positively associated with CAM usage, including herbs and supplements(Bonacchi et al.,2014).Similarly, younger cancer patients may be more likely to prefer biological alternative medicines, such as plant-based medicines(Ciarlo et al.,2021).Reasons for these differences in the younger age may be better health, faster recovery after cancer, higher tolerance of side effects from treatment, and better abilities in searching for information.

Those participants who had been diagnosed at least 
Table 3. The Multivariable Analysis of Factors Associated with Demand to MC Use among cancer patients in the Northern of Thailand. $(\mathrm{n}=1,284)$

\begin{tabular}{|c|c|c|c|c|c|c|}
\hline Factors & Number & $\%$ Demand to MC use & Crude OR & Adjust OR & $95 \% \mathrm{CI}$ & P-value \\
\hline Age (years) & & & & & & 0.005 \\
\hline$\geq 30$ & 1,244 & 43.09 & 1 & 1 & - & \\
\hline$<30$ & 40 & 72.5 & 3.48 & 1.89 & $1.21-2.93$ & \\
\hline \multicolumn{3}{|c|}{ Time from diagnosis with cancer (month) } & & & & 0.004 \\
\hline$<12$ & 1,072 & 42.63 & 1 & 1 & - & \\
\hline$\geq 12$ & 212 & 50.94 & 1.39 & 1.73 & $1.19-2.52$ & \\
\hline Social support & & & & & & $<0.001$ \\
\hline Low & 467 & 17.77 & 1 & 1 & - & \\
\hline Moderate to high & 817 & 59 & 6.65 & 5.5 & $3.60-8.39$ & \\
\hline Attitude toward MC use & & & & & & $<0.001$ \\
\hline Poor & 360 & 21.67 & 1 & 1 & - & \\
\hline Fair to Good & 924 & 52.71 & 4.02 & 2.56 & $1.83-3.56$ & \\
\hline Health literacy about MC & & & & & & $<0.001$ \\
\hline Inadequate/ Problematic & 915 & 28.85 & 1 & 1 & - & \\
\hline Adequate/ Excellent & 369 & 81.57 & 10.91 & 5.7 & $4.08-7.96$ & \\
\hline
\end{tabular}

12 months earlier were 1.73 times more likely to report demand for MC use when compared with those diagnosed less than to 12 months. Previous studies have reported that time from diagnosis with cancer was positively correlated with CAM use in cancer patients (Truant et al., 2013). One possibleexplanation is that when a person transitions to chronic illness, they begin searching for information on how to take care of their own health, in turn increasing their health literacy, resulting in a decision to use MC.

This cross-sectional study found that $44.0 \%$ of cancer patients in the North of Thailandreported demand to use MC. The significant factors associated with reported demand to use MC were adequate to excellent levels of health literacy on MC use,moderate to high level of social support, fair to good attitudes about MC use, younger age, and longer time from diagnosis with cancer controlling for other covariates.

\section{Author Contribution Statement}

All authors contributed equally to this work.

\section{Acknowledgements}

We extend our sincere thanks to the cancer patients who agreed to participate. Moreover, thank you very much for Faculty of Public Health, KhonKaen University, Thailand, for their constant encouragement and support. The authors thank all the patients who participated in the study.

\section{Approval}

The current study deals with primary data, so it doesn't need from approval of scientific body. This paper is a part of the dissertation submitted in fulfillment of the requirements for the degree of Doctor of Public Health Program, Faculty of Public Health, Khon Kaen University, Thailand.

\section{Funding Statement}

The research is not funded by a specific project grant, but rather from personal fund of the authors.

\section{Availability of data}

The datasets are not publicly available due to ethical restrictions but are available from the corresponding author on reasonable request.

\section{Conflict of interest}

All authors declared no conflict of interest.

\section{References}

Abrams DI, Guzman M (2015). Cannabis in cancer care. Clin Pharmacol Ther, 97, 575-86.

American Cancer Society (2016). Cancer Treatment and Survivorship Facts and Figures 2016-2017. Available at: cancer-treatment-and-survivorship-facts-andfigures-2016-2017.pdf Accessed on 27/04/2021.

Ayele AA, Tegegn HG, Haile KT, et al (2017). Complementary and alternative medicine use among elderly patients living with chronic diseases in a teaching hospital in Ethiopia. Complement Ther Med, 35, 115-9.

Bains SS, Egede LE (2011). Association of health literacy with complementary and alternative medicine use: a cross-sectional study in adult primary care patients. $B M C$ Complement Altern Med, 11, 138.

Bauml JM, Chokshi S, Schapira MM, et al (2015). Do attitudes and beliefs regarding complementary and alternative medicine impact its use among patients with cancer? A cross-sectional survey. Cancer, 121, 2431-8.

Bonacchi A, Fazzi L, Toccafondi A, et al (2014). Use and perceived benefits of complementary therapies by cancer patients receiving conventional treatment in Italy. J Pain Symptom Manage, 47, 26-34.

Bursac Z, Gauss CH, Williams DK, Hosmer DW (2008). Purposeful selection of variables in logistic regression. Source Code Biol Med, 3, 1-8.

Cancer control. Knowledge into action. WHO guide for effective programmes. Module 4 Cancer Control: Knowledge into 
Action: WHO Guide for Effective Programmes: Module 4: Diagnosis and Treatment. Geneva: World Health Organization; 2008. KEY MESSAGES. Available from: https://www.ncbi.nlm.nih.gov/books/NBK179050/2008 [

Choi JY, Ji W, Choi CM, et al (2021). Awareness and use of complementary and alternative medicine in Korean lung cancer patients. Tuberc Respir Dis, 84, 105-114.

Ciarlo G, Ahmadi E, Welter S, Hübner J (2021). Factors influencing the usage of complementary and alternative medicine by patients with cancer. Complement Ther Clin Pract, 44, 101389.

Haug NA, Padula CB, Sottile JE, et al (2017). Cannabis use patterns and motives: A comparison of younger, middleaged, and older medical cannabis dispensary patients. Addict Behav, 72, 14-20.

Kristoffersen AE, Quandt SA, Stub T (2021). Use of complementary and alternative medicine in Norway: a crosssectional survey with a modified Norwegian version of the international questionnaire to measure use of complementary and alternative medicine (I-CAM-QN). BMC Complement Altern Med, 21, 93.

Labidi S, Ennouri S, Rachdi H, et al (2020). Use of complementary and alternative medicine in cancer: A Tunisian single-center experience. Bulletin Du Cancer, 107, 209-24.

Lal S, Shekher A, Puneet Narula AS, Abrahamse H, Gupta SC (2021). Cannabis and its constituents for cancer: History, biogenesis, chemistry and pharmacological activities. Pharmacol Res, 163, 105302.

Leos-Toro C, Shiplo S, Hammond D (2018). Perceived support for medical cannabis use among approved medical cannabis users in Canada. Drug Alcohol Rev, 37, 627-36.

Markham MJ, Wachter K, Agarwal N, et al (2020). Clinical cancer advances 2020: Annual Report on Progress Against Cancer from the American Society of Clinical Oncology. J Clin Oncol, 38, 1081.

Martell K, Fairchild A, LeGerrier B, et al (2018). Rates of cannabis use in patients with cancer. Curr Oncol, 25, 219-25.

Naja F, Fadel RA, Alameddine M, et al (2015). Complementary and alternative medicine use and its association with quality of life among Lebanese breast cancer patients: a crosssectional study. BMC Complement Altern Med, 15, 444. https://doi.org/10.1186/s12906-015-0969-9.

Organization WH. Cancer. https://www.who.int/health-topics/ cancer\#tab=tab_12021.

Organization WH. Thailand. Burden of cancer. https:/www.who. int/cancer/country-profiles/THA 2020.pdf2020.

Parker PD, Heiney SP, Adams SA, Friedman DB, Dawson RM (2020). Factors influencing chemotherapy knowledge in women with breast cancer. Appl Nurs Res, 56, 151335.

Rakpanich W, Panomai N, andLaohasiriwong W (2020). Determinants of intention to use medical cannabis among people in the northeast of Thailand. Indian J Public Health Res Dev, 11, 1475-81

Reblin M, Sahebjam S, Peeri NC, et al (2019). Medical cannabis use in glioma patients treated at a comprehensive cancer center in Florida. $J$ Palliat Med, 22, 1202-7.

Saengkham S, Ongkasingh C (2020). Myth and meaning of cannabis in Thai society. J Communicat Arts Rev, 24, 193206.

SharoniSKA, Robani S, andZaini SA (2019). Use of complementary and alternative medicine: Prevalence and health literacy among patients attending a Health Centre in UniversitiTeknologi MARA Selangor. Healthscope: The Official Research Book of Faculty of Health Sciences, UiTM, 1. Retrieved from https://healthscopefsk.com/index. $\mathrm{php} / \mathrm{research} / \mathrm{article} / \mathrm{view} / 8$.

Sexton M, Cuttler C, Finnell JS, Mischley LK (2016). A cross-

\section{Demand for Medical Cannabis Use in Northern Thailand}

sectional survey of medical cannabis users: Patterns of Use and Perceived Efficacy. Cannabis Cannabinoid Res, 1, 131-8.

Smith CA, Chang E, Gallego G (2019). Complementary medicine use and health literacy in older Australians. Complement Ther Med, 42, 53-8.

Suphanchaimat R, Pavasuthipaisit C (2018). Situation review on potential benefits and risks from medicalisation and legalisation of cannabis. Available at: http://ihppthaigov.net/ DB/publication/attachresearch/394/chapter1.pdf.

Tangkiatkumjai M, Boardman H, Walker DM (2020). Potential factors that influence usage of complementary and alternative medicine worldwide: a systematic review. $B M C$ Complement Med Ther, 20, 363.

Tringale KR, Shi Y, Hattangadi JA (2017). Marijuana utilization in cancer patients: A Comprehensive Analysis of National Health and Nutrition Examination Survey Data from 20052014. Int J Radiat Oncol Biol Phys, 99, S11.

Truant TL, Porcino AJ, Ross BC, WongME, Hilario CT (2013). Complementary and alternative medicine (CAM) use in advanced cancer: a systematic review. J Support Oncol, 11, 105-13.

Virani S, Bilheem S, Chansaard W, et al (2017). National and subnational population-based incidence of cancer in Thailand: Assessing Cancers with the Highest Burdens. Cancers, 9, 108.

von Conrady DM, Bonney A (2017). Patterns of complementary and alternative medicine use and health literacy in general practice patients in urban and regional Australia. Aust Fam Physician, 46, 316-20

Vos T, Lim SS, Abbafati C, et al (2020). Global burden of 369 diseases and injuries in 204 countries and territories, 19902019: a systematic analysis for the Global Burden of Disease Study 2019. Lancet, 396, 1204-22.

Whiting PF, Wolff RF, Deshpande S, et al (2015). Cannabinoids for medical use: A Systematic Review and Meta-analysis. JAMA, 313, 2456-73.

Yarney J, Donkor A, Opoku SY, et al (2013). Characteristics of users and implications for the use of complementary and alternative medicine in Ghanaian cancer patients undergoing radiotherapy and chemotherapy: a cross- sectional study. $M C$ Complement Altern Med, 13, 16.

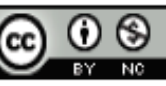

This work is licensed under a Creative Commons AttributionNon Commercial 4.0 International License. 